\title{
VALIDATION OF A NEW INTRAOPERATIVE TECHNIQUE TO EVALUATE LOAD-INDEPENDENT INDICES OF RIGHT VENTRICULAR PERFORMANCE IN PATIENTS UNDERGOING CARDIAC OPERATIONS
}

Carl I. O. Brookes, MRCP

Paul A. White, MSc

Andrew J. Bishop, MRCP

Paul J. OIdershaw, FRCP

Andrew N. Redington, FRCP

Neil E. Moat, FRCS

\begin{abstract}
Background: Assessment of right ventricular performance in the perioperative period is difficult because there is no generally accepted method of measuring right ventricular volume. We set out to determine whether conductance technology could provide a valuable technique for the investigation of intraoperative right ventricular function. Methods and results: Three validating studies were performed in 25 patients undergoing routine coronary revascularization. Study 1 : The influence of conductance catheter position in the right ventricle was examined in 10 patients. Insertion of the conductance catheter through the outflow tract was associated with a larger gain constant and a smaller parallel conductance compared with insertion through the tricuspid valve. Study 2: The reproducibility of contractility measurements with the use of a conductance catheter was examined in 7 additional patients. Removal and reinsertion of the conductance catheter was not associated with any significant difference in right ventricular volume or contractile function. Study 3: Right ventricular performance before and after cardiopulmonary bypass was compared in 8 additional patients. There was a fall in the slope of the right ventricular preload recruitable stroke work from $15.6(3.8)$ to $11.0(5.1) \mathrm{mm} \mathrm{Hg}(P=.01)$ and an increase in the slope of the end-diastolic pressure-volume relations from $0.05(0.02)$ to $0.11(0.05) \mathrm{mm} \mathrm{Hg} / \mathrm{mL}(P=.001)$. Conclusions: The conductance technique can be used to study perioperative changes in right ventricular performance. Insertion of the conductance catheter through the outflow tract provides stable and reproducible data. There is significant impairment of right ventricular contractility in the early postoperative period. (J Thorac Cardiovasc Surg 1998;116:468-76)
\end{abstract}

$P^{2}$ erioperative right ventricular (RV) function has important prognostic implications for patients undergoing several cardiac surgical procedures. ${ }^{1,2}$

From the Department of Pediatric Cardiology, Royal Brompton National Heart/Lung Institute, Royal Brompton Hospital, London, United Kingdom.

Supported in part by the Garfield Weston Trust (C.I.O.B.) and by the Scott Rhodes Research Fund, the Clinical Research Committee of the Royal Brompton, and the Garfield Weston Trust

Received for publication Jan 7, 1998; revisions requested March 16, 1998; revisions received April 17, 1998; accepted for publication May 13, 1998.

Address for reprints: Andrew N. Redington, MD, Department of Pediatric Cardiology, Royal Brompton National Heart/Lung Institute, Sydney St, Chelsea, London SW3 6NP, United Kingdom.

Copyright $(1998$ by Mosby, Inc.

$0022-5223 / 98 \$ 5.00+0 \quad \mathbf{1 2 / 1 / 9 1 6 3 5}$
Maintaining optimal function in the perioperative period requires careful myocardial protection dur ing cardiopulmonary bypass (CPB), but there is evidence that standard cardioplegic techniques do not adequately protect the RV function, particularly in the context of RV hypertrophy and coronary artery disease. . $^{3-6}$

Assessment of RV performance at this time is difficult because there is no generally accepted method of measuring RV volume and because routinely measured indices of function (eg, ejection fraction and maximum rate of rise of ventricular pressure) are all critically load dependent. The conductance technique has been used to overcome the same problems when left ventricular (LV) performance is being assessed; but to date, there are no data concerning its use in the RV of patients undergoing cardiac operation.

Although experimental and human RV data have 
been obtained under other circumstances, the intraoperative use of conductance catheters in the RV remains subject to a number of theoretic limitations. First, measurement of $\alpha$, defined as the ratio of conductance-derived volumes to true ventricular volumes, requires comparison against a gold standard, which is not readily available for the RV. Consequently, most studies have compared conductance stroke volumes with those derived from thermodilution or pulmonary artery flow probes and extrapolated absolute volumes from these values. ${ }^{7-9}$ Furthermore, $\alpha$ is dependent on the internal geometry of the RV cavity and on the position of the catheter in the ventricle, both of which can change during the course of an operation. Second, the parallel conductance is also markedly dependent on the experimental setting in which it is measured and it has been suggested that the thin RV myocardium may allow greater current leakage from the cavity. This would result in a larger parallel conductance $(\mathrm{Vc})$ and potentially introduces greater errors into absolute volume estimations. ${ }^{10}$ Finally, conductance theory dictates that accurate volume measurements can only be obtained if the catheter lies along the central axis of an interrogated chamber. The RV cavity, however, has 2 separate axes (one from the tricuspid valve to RV apex and one from RV apex to outflow tract), and it may therefore not be possible for a single conductance catheter to interrogate both axes simultaneously.

We conducted 3 validating studies to examine the clinical utility of this novel approach to the intraoperative assessment of RV performance: study 1 , to determine the influence of catheter position within the RV cavity, on alpha $(\alpha), \mathrm{Vc}$, and the calculated $\mathrm{RV}$ volume; study 2 , to assess the reproducibility of these data in the clinical setting; and study 3 , to apply the findings to the examination of RV contractile function immediately after CPB in patients undergoing coronary artery operation.

\section{Patients and methods}

All studies were performed in patients undergoing routine revascularization for stable coronary disease. All had 3 vessel coronary diseases with good LV function (ejection fraction $>50 \%$ ). Twenty-four of the 25 patients had a dominant right coronary circulation that was completely occluded (14 patients) and severely diseased (10 patients). The studies conformed to the principles outlined in the Declaration of Helsinki and the protocols were approved by the hospital ethics committee.

Study 1: Influence of catheter position. Ten patients were studied. After sternotomy and before $\mathrm{CPB}$, a $6 \mathrm{~F}$ pigtail conductance catheter (Cordis Webster, Inc, Bald- win Park, Calif) and a $2.5 \mathrm{~F}$ micromanometer (Millar Instruments, Inc, Houston, Tex) were inserted into the $\mathrm{RV}$ apex via 2 different routes-either through the right atrium (RA) via the right atrial appendage and tricuspid valve or through a small incision in the $R V$ outflow tract (RVOT) as close to the pulmonary valve as possible. The $\mathrm{RA}$ route was studied first in all cases. We used conductance catheters with a total interelectrode distance of 6 to $8 \mathrm{~cm}$, depending on RV size. Correct positioning of the pigtail catheter in the ventricular apex was determined by palpation and confirmed by demonstration of pressure and segmental volume signals with appropriate phase relationships.

Cardiac output and stroke volume were estimated by thermodilution. A 7F flotation thermodilution catheter (Arrow International, Inc, Reading, Pa) was used, and cardiac output was assessed conventionally with an injection of $10 \mathrm{~mL}$ of cold saline solution into the right atrial port. Measurements were repeated until 3 readings were within $10 \%$ of one another. The stroke volume obtained by this method was used to determine $\alpha$ (= conductance stroke volume/thermodilution stroke volume). Vc was estimated by a modification of the hypertonic saline solution injection method developed by Baan and colleagues. ${ }^{11}$ A slow bolus of $7 \mathrm{~mL}$ of $10 \%$ saline solution was injected into the superior vena cava (SVC) causing a transient change in conductivity of the blood within the RV cavity without any detectable change in RV pressure.

Study 2: Reproducibility of RVOT measurements. The effect of small changes of catheter position within the RV on the pressure-volume data was assessed by removal and replacement of the catheter through the RVOT in 7 additional patients. The RA route was not studied. The protocol was identical to that described in study 1 . Baseline values of $\alpha, \mathrm{Vc}$, end-diastolic volume (EDV), and contractile function were compared with those obtained after the catheter had been removed and replaced through the same incision. Repeat measurements were obtained immediately and were not associated with any significant change in the hemodynamic variables. Loadindependent indices of ventricular performance, such as the slope of the end-systolic pressure-volume relations (ESPVR) and preload recruitable stroke work (PRSW) were determined by gradual preload reduction with a snare placed around the SVC. All measurements were obtained in duplicate, and the mean of the two values were used for comparison.

Study 3: The effect of CPB on RV performance. In an additional 8 patients, RV function was compared before and after $\mathrm{CPB}$, with the pericardium opened. The protocol before CPB was identical to that described in study 2 , except that an integrated custom-made conductance catheter and micromanometer (Millar Instruments) was used. After baseline data had been collected in duplicate, the conductance catheter was removed and the patient was put onto CPB. Myocardial protection was achieved with ventricular fibrillation with intermittent aortic crossclamping. After revascularization, the conductance catheter was reinserted through the same incision in the RVOT, and the patient was weaned from CPB. Pressure-volume data were recorded in duplicate immediately, then again approximately 15 minutes later, after protamine had been 
Table I. Data from patients in study 1: comparison of $O T$ and $R A$ routes of catheter insertion

\begin{tabular}{|c|c|c|c|c|c|c|c|c|}
\hline Patient & $\alpha(O T)$ & $\alpha(R A)$ & $\begin{array}{c}\text { Diff } \alpha \\
(O T)\end{array}$ & $\begin{array}{c}\text { Diff } \alpha \\
(R A)\end{array}$ & $\begin{array}{c}V c \\
(O T)\end{array}$ & $\begin{array}{c}V c \\
(R A)\end{array}$ & $\begin{array}{c}\text { Diff } V_{C} \\
(O T)\end{array}$ & $\begin{array}{c}\text { Diff } V_{C} \\
(R A)\end{array}$ \\
\hline 1 & 0.52 & 0.53 & 0.02 & 0 & 62.6 & 87.9 & 1.9 & 49.7 \\
\hline 2 & 0.24 & 0.35 & 0.04 & 0.04 & 60.7 & 133.4 & 4.0 & 33.2 \\
\hline 3 & 0.35 & 0.24 & 0.04 & 0 & 45.0 & 88.6 & 12.3 & 1.7 \\
\hline 4 & 0.61 & 0.4 & 0 & 0.06 & 135.6 & 101.7 & 54.4 & 67.1 \\
\hline 5 & 0.83 & 0.65 & 0.06 & 0.02 & 52.1 & 72.5 & 10.2 & 0.6 \\
\hline 6 & 0.72 & 0.42 & 0.01 & 0.03 & 126.6 & 132.0 & 1.9 & 5.5 \\
\hline 7 & 0.32 & 0.26 & 0 & 0.01 & 59.5 & 71.6 & 6.5 & 44.3 \\
\hline 8 & 0.54 & 0.39 & 0.02 & 0.03 & 55.1 & 82.1 & 1.0 & - \\
\hline 9 & 0.34 & 0.17 & 0.02 & 0.02 & 61.5 & 137.9 & 5.9 & - \\
\hline 10 & 0.70 & 0.49 & 0.01 & 0.04 & 79.4 & 45.3 & 5.3 & 65.8 \\
\hline
\end{tabular}

Diff $\alpha$, Difference between duplicatc $\alpha$ estimations; Diff $V c$, absolute difference between duplicate $V_{c}$ measurements in milliliters.

given. Thermodilution cardiac outputs and Vc estimations were also repeated after protamine.

The conductance catheter was removed before CPB in studies 1 and 2 and after the last set of data collection in study 3. Hemostasis was secured with a purse-string suture, and routine postoperative care was provided.

Data acquisition and analysis. The amplified pressure signal (Fylde Isotransducer Amplifier, Preston, United Kingdom) was fed directly to a committed personal computer (Viglen Ltd, Alperton, United Kingdom) where it was combined with volume and electrocardiographic data in custom software.

The total conductance signal was generated and processed in a Sigma-5 DF unit (Cardiodynamics, Zoetermeer, The Netherlands). The principles of conductance catheter technology are described in detail elsewhere. ${ }^{11}$ In brief, the conductance catheter is a modified angiography catheter with a series of equally spaced electrodes at the distal end, designed so that the proximal and distal electrodes span as much of the ventricular cavity as possible. A $30-\mu \mathrm{A} 20-\mathrm{kHz}$ current is generated between the proximal and distal electrodes, and the intervening electrodes measure conductances between electrode pairs located in the RV. The conductances are summed and converted to a time-varying volume signal.

The volume $(\mathrm{V})$ of the ventricle at a given time $(\mathrm{t})$ is:

$$
V(t)=(1 / \alpha) L^{2} \mu[G(t)-G c]
$$

where $\mathbf{L}$ is the interelectrode distance, $\mu$ is the blood resistivity that is measured, and $G(t)$ is the sum of conductances at any time.

Care was taken to ensure that segmental conductance changes were in phase to exclude the possibility of atrial sampling when the transtricuspid route was used.

The pressure and volume data were sampled at $250 \mathrm{~Hz}$ and transferred through a 12-bit, 16-channel, A to D converter into custom software and calculations of $\alpha, \mathrm{Vc}$, corrected EDV, and contractile function were made offline.

All measurements were made in duplicate with ventilation held at end-expiration and then averaged. In addition, in study 1 the absolute difference between duplicate measurements from each route was compared. Thus, conductance stroke volumes were determined from 2 recordings at steady state. In each recording, the maximum and minimum volume for 5 consecutive cardiac cycles was identified, and the stroke volume for that run was defined as the mean difference between maximum and minimum volumes. This was then repeated for the second recording, and the mean of the 2 stroke volumes was divided by the thermodilution stroke volume to yield $\alpha$.

Similarly, two injections of hypertonic saline solution were used to calculate Vc. End-systolic and end-diastolic volumes (ESV and EDV) from individual cardiac cycles during the saline solution injection were plotted, and the lines were regressed to the point where ESV = EDV; this volume was taken as Vc. The correlation coefficient for the regression line was recorded as an index of precision; coefficients of less than 0.9 were not accepted.

Calculation of contractile function during SVC snaring was performed with at least 5 consecutive cardiac cycles. The ESPVR slope was determined by linear regression from the points of maximum pressurc/volume in each cycle during the snare. The PRSW slope was calculated from the plot of stroke work against EDV (defined by the electrocardiogram $R$ wave). The end-diastolic pressurevolume relation (EDPVR) slope was determined by both linear and exponential regression of the same pressurevolume data at end-diastole according to the equations $p=a \mathrm{~V}+c$ and $\mathrm{p}=\mathrm{A} e^{\mathrm{BV}}$, where $p=$ pressure $(\mathrm{mm} \mathrm{Hg})$, $\mathrm{V}=$ volume $(\mathrm{mL}), a=$ slope of linear $\mathrm{p} / \mathrm{v}$ relation $(\mathrm{mm}$ $\mathrm{Hg} / \mathrm{mL}$ ), and $\mathrm{B}=$ myocardial stiffness constant. The data presented are therefore for the constants $a$ and B.

Statistics. Paired values of $\alpha$ and Vc were compared with Wilcoxon's sign rank test. Absolutc differences between duplicate measurements and comparisons before and after CPB were made with the paired Student's $t$ test.

\section{Results}

\section{Study 1: Influence of catheter position}

Parallel conductance (Table I). The mean ( \pm SD) $\mathrm{Vc}$ from the RVOT was $73.8 \pm 31.5 \mathrm{~mL}$ versus $99.1 \pm 25.8 \mathrm{~mL}$ for the $\mathrm{RA}$ route, $P=.025$. The mean absolute difference between duplicate measurements from the RVOT and RA were $10.1 \pm 5.1$ $\mathrm{mL}$ and $33.5 \pm 9.8 \mathrm{~mL}$, respectively; $P=.04$. 


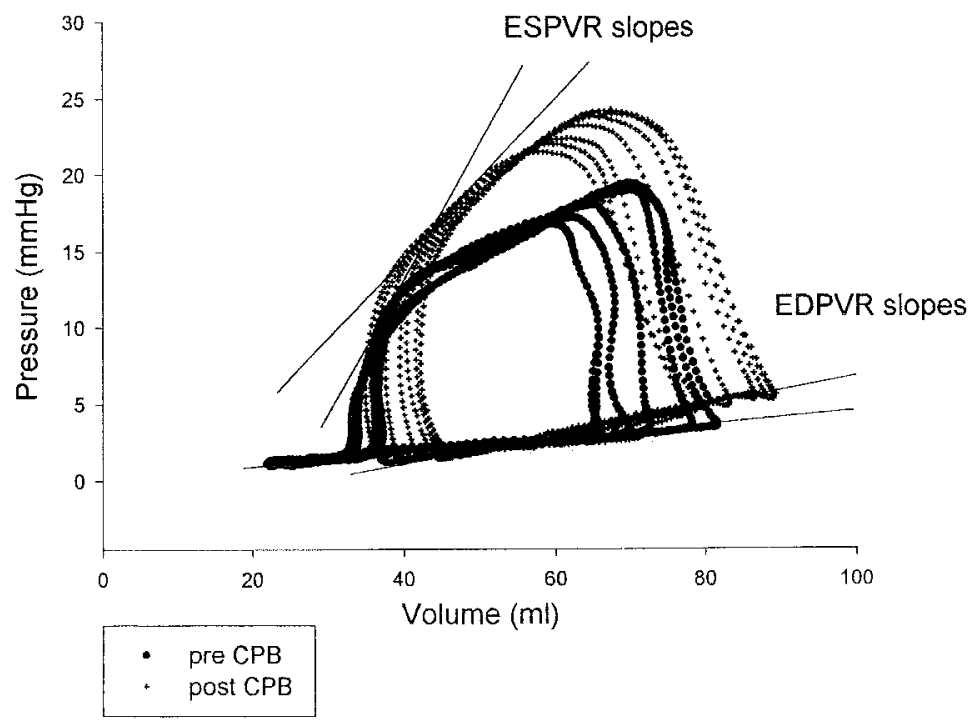

Fig. 1. RV pressure-volume cycles during SVC snaring before and immediately after CPB.

There was no correlation between the difference in duplicate estimations of $\mathrm{Vc}$ and the absolute value of $\mathrm{Vc}$ from the RA route, $r=-0.05, P=.449$ (although the existence of such a relationship was suggested from the RVOT data, $r=0.59, P=.07$ ).

The regression coefficient for $\mathrm{Vc}$ estimations was more than 0.91 in $92 \%$ of measurements, and there was no significant difference between routes.

Duplicate data were available from the RVOT in all patients; but, because of poor data quality $(r<$ 0.85 ), single values only had to be accepted from the RA route in 2 patients.

Gain constant, $\alpha$ (Table I). Duplicate data were available from both routes in all patients. The mean $\alpha$ ( $\pm \mathrm{SD})$ for the RVOT was $0.52 \pm 0.2$ and for the RA was $0.39 \pm 0.17, P=.01$.

The mean absolute difference between duplicate measurements for the RVOT was $0.02 \pm 0.02$ and for the RA was $0.03 \pm 0.02, P=.73$

Absolute RVEDVs. The corrected EDV with the mean values of duplicate $\alpha$ and $\mathrm{Vc}$ were similar for both routes: $\mathrm{RA}=118.2 \pm 50.1 \mathrm{~mL}$; $\mathrm{RVOT}=$ $112.5 \pm 44.1 \mathrm{~mL} ; P=.34$. Meaningful volumes were not obtainable from 2 patients via the RA route because of difficulties with $\mathrm{Vc}$ estimation.

The SVC snare. The SVC was chosen as the site of the venous snare because it is more accessible than the IVC and more easily repairable in the event of a tear during mobilization. There were no such complications during these studies, and the application of the snare produced a significant, but variable, preload reduction. The mean stroke work reduction was $44 \%$ (range, $5.6 \%$ to $91.1 \%$ ), but the change in EDV was much smaller, approximately $5 \%$.

Technical considerations. Correct positioning of the conductance catheter is technically much easier through the RVOT than through the RA, mainly because the RV free wall is easily accessible. We also found that the data obtained via the RVOT were both of superior quality and more reproducible than those from the RA route (Table I). There were no complications associated with this study. Blood loss was reduced by the use of purse-string sutures at both sites of insertion and was negligible, particularly during insertion through the RVOT.

The shape of the pressure-volume relations from both routes was similar within individual patients. Most patients had poorly defined periods of either isovolumic contraction or relaxation resulting in the characteristic "triangular" or "trapezoid" pressurevolume loops (Fig. 1). Only 1 patient had "square" loops, and this finding could not be explained by the presence of either pulmonary hypertension or acute ischemia.

Study 2: Reproducibility of RVOT measurements. As a group there were no significant differences in any of the parameters measured when baseline data were compared with those made after removing and replacing the conductance catheter (Table II). Similarly, within individuals there was no systematic difference between the 2 measurements. The mean difference between baseline and repeat measure- 
Table II. Data from patients in study 2: changes after removal and reinsertion of the conductance catheter

\begin{tabular}{lrrc}
\hline & Baseline & \multicolumn{1}{c}{ Repeat } & P value \\
\hline$\alpha$ & $0.43 \pm 0.27$ & $0.44 \pm 0.29$ & .85 \\
Vc $(\mathrm{ml})$ & $82.8 \pm 30.8$ & $88.5 \pm 27.9$ & .29 \\
Corr EDV $(\mathrm{mL})$ & $139.8 \pm 47.3$ & $129.0 \pm 28.9$ & .30 \\
ESPVR $(\mathrm{mm} \mathrm{Hg} / \mathrm{mL})$ & $0.35 \pm 0.13$ & $0.36 \pm 0.16$ & .73 \\
PRSW $(\mathrm{mm} \mathrm{Hg})$ & $14.81 \pm 9.7$ & $16.1 \pm 10.2$ & .23
\end{tabular}

All data are mean \pm SD.

Corr EDV, End-diastolic volume corrected for $\alpha$ and $\mathrm{Vc}$.

ments was $12.7 \% \pm 10.8 \%$ for the PRSW and $15.3 \%$ $\pm 13.2 \%$ for the ESPVR. In 2 patients the corrected EDV fell by $50 \mathrm{~mL}$ during the repeat measurements, but this was associated with only a small change in contractile function.

These results suggest that small changes in catheter position that are inevitable after removal and reinsertion do not significantly affect indices of contractile function or their measurement.

Study 3: The effect of CPB on RV performance. After CPB there was a significant change in both systolic and diastolic indices of RV performance with an increase in both EDV and ESV, a fall in the stroke volume, a fall in the slope of the PRSW, and an increase in the slope of the linear EDPVR. There was a tendency for the ESPVR slope to fall and the exponential EDPVR slope to increase, but these changes did not reach significance.

The mean ( \pm SD) RVEDV increased from $118.4 \pm 33.2 \mathrm{~mL}$ to $153.9 \pm 36.4 \mathrm{~mL}, P=.03$; and the ESV increased from $61.6 \pm 28.7 \mathrm{~mL}$ to $102.9 \pm$ $38.1 \mathrm{~mL}, P=.025$. The slope of the PRSW fell from $15.6 \pm 3.8 \mathrm{~mm} \mathrm{Hg}$ to $11.0 \pm 5.1 \mathrm{~mm} \mathrm{Hg}, P=.01$; the linear EDPVR slope increased from $0.05 \pm 0.02$ $\mathrm{mm} \mathrm{Hg} / \mathrm{mL}$ to $0.14 \pm 0.06 \mathrm{~mm} \mathrm{Hg} / \mathrm{mL}, P=.001$; and the exponential EDPVR slope increased from $0.019 \pm 0.027$ to $0.065 \pm 0.099, P=.16$. The slope of the ESPVR fell from $0.5 \pm 0.09 \mathrm{~mm} \mathrm{Hg} / \mathrm{mL}$ to $0.38 \pm 0.16 \mathrm{~mm} \mathrm{Hg} / \mathrm{mL}, P=.29$ (Table III; Figs. 1 and 2).

After protamine administration, there was no further change in the parameters measured. The EDV was $154.4 \pm 48.6 \mathrm{~mL}$; the ESV, $107.6 \pm 30.9$ $\mathrm{mL}$; the PRSW, $10.5 \pm 4.3 \mathrm{~mm} \mathrm{Hg}$; the linear EDPVR, $0.11 \pm 0.05 \mathrm{~mm} \mathrm{Hg} / \mathrm{mL}$; and the ESPVR, $0.39 \pm 0.1 \mathrm{~mm} \mathrm{Hg} / \mathrm{mL}$.

\section{Discussion}

Although not previously used in patients undergoing cardiac operation, the conductance catheter has been used to assess relative changes in RV volumes in both human beings, ${ }^{9,}$ and animals, ${ }^{10,15,16}$ and it is clear from our data that plots of the relative changes in RV pressure and volume can be obtained in human beings in the intraoperative setting. The potential power of this technique, however, is in the estimation of absolute ventricular volume, which is essential for the determination of load-independent indices of ventricular function. Clearly further validation was required before its clinical application could be recommended. The aim of this paper was to provide some of these validation data and to examine the utility of the conductance technique in the period before an operation.

Study 1: The influence of catheter position. Because of technical limitations, measurement of absolute RV volumes from conductance catheters requires calibration. In the absence of an obvious calibrating technique, most studies, including ours, have compared conductance measurements with those obtained by either thermodilution or ultrasonic pulmonary artery flow probes $^{7-9}$ and have either then extrapolated EDV from these measurements or not attempted to estimate absolute volumes at all. Although this extrapolation may not be entirely valid, as $\alpha$ has been demonstrated to show a degree of volume dependence in both the $\mathrm{LV}$ and $\mathrm{RV}$, our study was concerned with comparisons of $\alpha$ at steady state derived from 2 different routes of catheter insertion. We believe, therefore, that these measurements are valid because any absolute volume error should apply to both routes studied.

Our values for $\alpha, 0.5 \pm 0.2$ from the RVOT and $0.39 \pm 0.17$ from the $\mathrm{RA}$, in study 1 are similar to those we have described previously ${ }^{19}$ and are comparable to those reported by Woodard, ${ }^{16}$ Stamato, ${ }^{8}$ Maloney ${ }^{9}$ and their colleagues in the RV of greyhounds, small pigs, and human beings, respectively. These values, as expected, are somewhat lower than those seen in the LV. We have demonstrated that $\alpha$ is significantly higher when the catheter is inserted into the RV apex from the RVOT, suggesting that more of the ventricular cavity is interrogated via this route. These findings are in agreement with the only other study to examine the effect of catheter position on conductance-derived volume changes in the $\mathrm{RV}^{16}$

$\mathrm{Vc}$ in the RV has been reported to be $32.3 \pm 6.3$ $\mathrm{mL}$ in $16-\mathrm{kg} \mathrm{pigs}^{8}$ and $79.1 \pm 18.6 \mathrm{~mL}$ in $40-\mathrm{kg}$ pigs. ${ }^{10}$ In patients with congenital heart disease, we have previously found a Vc of $89.7 \pm 43.7 \mathrm{~mL}$ and have shown that $\mathrm{Vc}$ is not significantly different at 

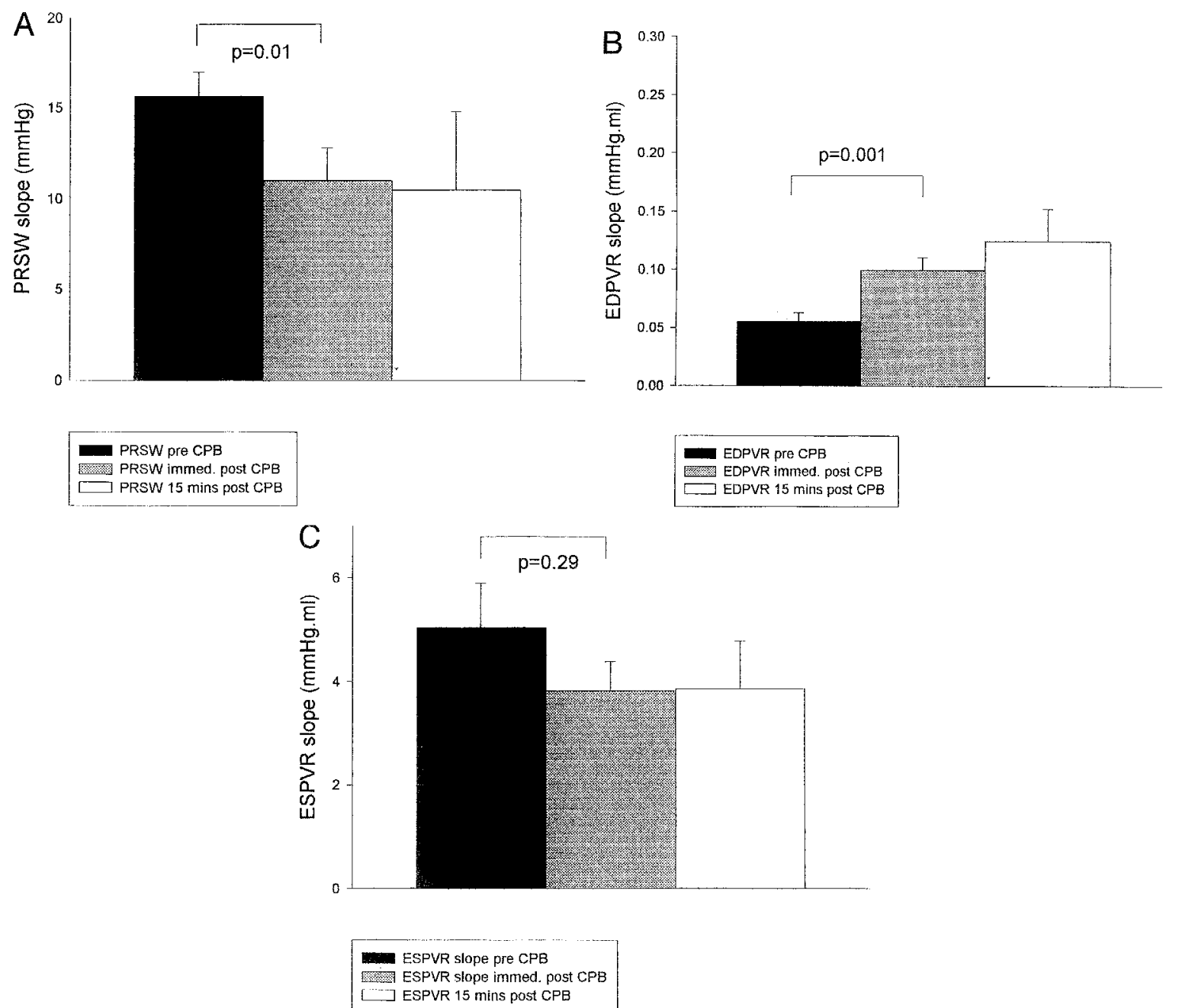

Fig. 2. A, Changes in the slope of PRSW after CPB. B, Changes in the slope of linear EDPVR after CPB.

C, Changes in the slope of ESPVR after CPB.

end-systole and end-diastole. ${ }^{20}$ The results reported here, in open-chest ischemic patients, are similar in magnitude to those described earlier but, more interestingly, demonstrate that catheter position within the ventricle significantly affects the size of the parallel conductance. Of more importance than the absolute values of $\mathrm{Vc}$, however, is the finding that the reproducibility of $\mathrm{Vc}$ estimation is also superior from the RVOT: a $10.1 \pm 5.1 \mathrm{~mL}$ versus $33.5 \pm 9.8 \mathrm{~mL}$ difference between duplicate Vc estimations will clearly have implications for the detection of small changes in contractile performance. The reason for the larger variability from the RA is probably not related to the larger absolute Vc because there was no correlation between difference in duplicate measurements and absolute $\mathrm{Vc}(r=-0.05, P=.449)$ but is more likely explained by the poorer quality of volume data resulting in a decreased signal to noise ratio.

Study 2: variability of contractility indices. Although we were able to derive a figure for the EDV using both $\alpha$ and $\mathrm{Vc}$, we have no way of estimating its accuracy. Nevertheless, because there is no other technique capable of providing beat-to-beat pressure-volume changes, the repeatability of EDV measurements becomes more important than a systematic error in absolute EDV. Using the RVOT route we were able to demonstrate that both the ESPVR and PRSW were reproducible. The $12.7 \%$ $\pm 10.8 \%$ and $15.3 \% \pm 13.2 \%$ difference between baseline and repeat slopes of the PRSW and ESPVR, respectively, are similar to those reported previously. Karunanithi and colleagues ${ }^{21}$ found a $7.8 \%$ $\pm 3.3 \%$ and $10.1 \% \pm 6.7 \%$ difference between 3 
Table III. Data from patients in study 3: changes in parameters after cardiopulmonary bypass

\begin{tabular}{|c|c|c|c|c|c|c|c|c|}
\hline Patient & $\begin{array}{l}\text { Before EDV } \\
(m L)\end{array}$ & $\begin{array}{l}\text { After } E D V \\
(m L)\end{array}$ & $\begin{array}{l}\text { Before PRSW } \\
\quad(m m \mathrm{Hg})\end{array}$ & $\begin{array}{l}\text { After PRSW } \\
\text { (mm } \mathrm{Hg})\end{array}$ & $\begin{array}{c}\text { Before EDPVR } \\
(\mathrm{mm} \mathrm{Hg} / \mathrm{mL})\end{array}$ & $\begin{array}{l}\text { After EDPVR } \\
(\mathrm{mm} \mathrm{Hg} / \mathrm{mL})\end{array}$ & $\begin{array}{c}\text { Before } E S P V R \\
(m m \mathrm{Hg} / m L)\end{array}$ & $\begin{array}{l}\text { After ESPVR } \\
(\mathrm{mm} \mathrm{Hg} / \mathrm{mL})\end{array}$ \\
\hline 1 & 74.6 & 160.0 & 12.4 & 7.9 & 0.03 & 0.14 & 1.01 & 0.22 \\
\hline 2 & 120.7 & 174.1 & 17.2 & 13.1 & 0.05 & 0.19 & 0.33 & 0.39 \\
\hline 3 & 173.2 & 151.4 & 11.3 & 10.6 & 0.03 & 0.09 & 0.45 & 0.25 \\
\hline 4 & 123.5 & 193.5 & 10.4 & 5.2 & 0.04 & 0.15 & 0.36 & 0.59 \\
\hline 5 & 151.6 & 203.5 & 16.6 & 9.3 & 0.07 & 0.1 & 0.49 & 0.35 \\
\hline 6 & 79.4 & 120.4 & 18.5 & 18.2 & 0.10 & 0.26 & 0.69 & 0.63 \\
\hline 7 & 106.8 & 98.4 & 20.5 & 18.1 & 0.04 & 0.09 & 0.43 & 0.41 \\
\hline 8 & 197.7 & 130.0 & 18.2 & 5.5 & 0.04 & 0.08 & 0.27 & 0.21 \\
\hline
\end{tabular}

repeated measures of PRSW and ESPVR using sonomicrometry in dogs, but it is of note that in this study the ultrasonic crystals were not moved between estimations. In 2 patients, however, there was a marked reduction in the EDV when the conductance catheter was replaced, which could be due to blood loss sustained during this maneuver but is more likely explained by a change in catheter position within the cavity. Interestingly, this volume change was not associated with a marked shift in either the ESPVR or the PRSW; but, with such a small sample, it is not possible to draw any definite conclusions from this observation. Almost all studies that have examined contractility indices in either ventricle have used an inferior vena cava balloon to reduce preload. ${ }^{8,10,18,22}$ Although this technique is eminently suited to catheter laboratory studies, the sterile field in an operating theater creates problems for balloon manipulation, so we decided to investigate the possibility of using a snare placed around the SVC. Although careful mobilization of the vein is required, the procedure takes less than 2 minutes and allows both a gradual and a reproducible reduction in preload. Provided the snare is kept away from the RA-SVC junction, atrial ectopy can be kept to a minimum. With this method, the stroke work done by the RV can be reduced by a mean of $44 \%$ although a much smaller change in $\mathrm{EDV}$, of the order of $5 \%$, is observed. This relatively small change in EDV has previously been described and is probably due to changes in $\alpha$ in response to acute preload reduction. $8,17,18,23$ Because we were not using a pulmonary artery flow probe in this study, we were not able to confirm these findings. Acute preload reduction also results in changes to $\mathrm{Vc}$ in the $\mathrm{LV},{ }^{17}$ and it is possible that similar changes occurring in the $\mathrm{RV}$ are contributing to this phenomenon.

Study 3: Changes in RV function after CPB. There are many reports of apparent $R V$ dysfunction after CFB, 5, 64, 25 and it is thought that imperfect RV myocardial protection is at least partly respon- sible for these observations. These studies, however, have used a combination of thermodilution techniques and/or radionuclide angiography to derive indices of $\mathrm{RV}$ function that are dependent on preload, afterload, and contractile state, all of which can change significantly after CPB. It is therefore not appropriate to assume that changes in these ejection indices accurately reflect changes in the contractility of the RV myocardium. To date, there have been no studies that have directly examined RV contractile function after cardiac operation.

Detailed pressure-volume analysis, whether from sonomicrometry or conductance catheterization, allows derivation of "load-independent" indices of function, such as the ESPVR, PRSW, and maximum rate of rise of ventricular pressure-end diastolic volume relationship. ${ }^{26,27}$ Since they were proposed, however, a number of studies have questioned both the linearity and the afterload sensitivity of these parameters. ${ }^{28,29}$ In the $L V$, Little and colleagues ${ }^{28}$ concluded that if linearity, reproducibility, and load sensitivity were all considered then the PRSW relation was the most reliable index of LV contractility. Karunanithi and colleagues $^{21}$ found similar results in the $\mathrm{RV}$ of conscious dogs. We have demonstrated, for the first time, a significant decline in systolic RV function, characterized by a fall in the slope of the PRSW in the period immediately after CPB. This dysfunction was present for the duration of the study and was not affected by protamine administration. Of note is that the magnitude of the fall in PRSW and the standard deviation of our measurements are comparable with those reported with esmolol administration in experimental animals. ${ }^{10}$ There was a similar decline in the slope of the ESPVR, but this did not reach statistical significance, probably because of the greater variability in the measurement of this index and it is consistent with the findings reported earlier. ${ }^{21}$ 
There was a concomitant increase in the slope of the linear EDPVR, and when these relations were derived with the exponential model there was a similar trend, albeit statistically insignificant, for end-diastolic stiffness to increase. The ideal method for analysis of EDPVR is a subject of debate, ${ }^{30}$ particularly with the pericardium open; but we believe there is a significant myocardial contribution to the observed changes, at least in most patients (Fig. 1).

The cellular mechanism of this global dysfunction is unknown; but physical trauma, perioperative temperature, ischemia-reperfusion, and the indirect effects of CPB (eg, the initiation of a systemic inflammatory response) probably all contribute.

This study was not designed to assess the efficacy of the protection method used but does suggest that the conductance technique, particularly with the RVOT route of insertion, could be used to examine myocardial protection strategies and their effect on RV systolic and diastolic performance with the sensitivity obtainable in experimental animal preparations. 10

\section{Conclusion}

In conclusion we have demonstrated that, despite the theoretic limitations, conductance catheters can be used to assess RV pressure-volume relations in adult patients undergoing cardiac operation. Insertion of the catheter through the RVOT is not only technically easy and safe, but it also allows a more complete interrogation of the RV cavity and probably causes less distortion of the intraventricular fields. Using this technique, we have shown that the data are reproducible and have demonstrated, for the first time, an early decline in RV contractile performance after CPB.

\section{REFERENCES}

1. Ferrazzi P, McGiflin DC, Kirklin JW, Blackstone EH, Bourge RC. Have the results of mitral valve replacement improved? J Thorac Cardiovasc Surg 1986;92:186-97.

2. Cummings RG, Hull-Ryde E, Schumacher DJ, et al. Differential susceptibility of the left and right ventricles and interventricular septum to irreversible injury during total ischaemia. Surg Forum 1986;37:295-7.

3. Menasche P, Kucharski K, Mundler O, Veyssie L, Subayi J-B, Le Pimpec F, et al. Adequate preservation of right ventricular function after coronary sinus cardioplegia: a clinical study. Circulation 1989;89:19-24.

4. Fisk RL, Ghaswalla D, Gullbeau EJ. Asymmetrical myocardial hypothermia during hypothermic cardioplegia. Ann Thorac Surg 1982;34:318-24.

5. Stein KL, Breisblatt W, Wolfe C, Gasior T, Hardesty R.
Depression and recovery of right ventricular function after cardiopulmonary bypass. Crit Care Med 1990;18:1197-200.

6. Boldt J, Kling D, Dapper F, Hempelmann G. Myocardial temperature during cardiac operations: influence on right ventricular function. J Thorac Cardiovasc Surg 1990;100: $562-8$.

7. Woodard JC, Bertram CD, Gow BS. Right ventricular volumetry by catheter measurement of conductance. Pacing Clin Electrophysiol 1987;10:862-70.

8. Stamato TM, Szwarc RS, Benson LN. Measurement of right ventricular volume by conductance catheter in closed-chest pigs. Am J Physiol 1995;269:H869-76.

9. Maloney J, Khoury D, Simmons T, Wilkoff B, Morant V, Trohman R, et al. Effect of atrioventricular synchrony on stroke volume during ventricular tachycardia in man. Am Heart J 1992;123;1561-8.

10. Dickstein ML, Yano O, Spotnitz HM, Burkhoff D. Assessment of right ventricular contractile state with the conductance catheter technique in the pig. Cardiovasc Res 19956; 29:820-6.

11. Baan J, van der Welde E, Steendijk P, et al. Calibration and application of the conductance catheter for ventricular volume measurcment. Automedica 1989;11:357-65.

12. Markiewicz W, Sechtem U, Higgins C. Evaluation of the right ventricle by magnetic resonance imaging. Am Hcart $\mathrm{J}$ 1987;113:8-15

13. Redington AN, Gray HH, Hodson ME, Rigby ML, Oldershaw PJ. Characterisation of the normal right ventricular pressure-volume relation by biplane angiography and simultaneous micromanometer pressure measurements. $\mathrm{Br}$ Heart J 1988;59:23-30.

14. Khoury D, Mc Allister $\mathrm{H}$, Wilkoff $\mathrm{B}$, et al. Continuous right ventricular volume assessment by catheter measurement for antitachycardia system control. Pacing Clin Electrophysiol 1989;12:1918-26.

15. Solda PL, Pantaleo P, Perlini S, Calciati GF, Pinsky MR, Bernardi L. Continuous monitoring of right ventricular volume changes using the conductance catheter in the rabbit. J Appl Physiol 1992;73:1770-5.

16. Woodard JC, Bertram CD, Gow BS. Detecting right ventricular volume changes using the conductance catheter. Pacing Clin Electrophysiol 1992;15:2283-94.

17. Applegate RJ, Cheng CP, Little WC. Simultaneous conductance catheter and dimension assessment of left ventricle in the intact animal. Circulation 1990;81:638-48.

18. Boltwood CM, Appleyard RF, Glantz SA. Left ventricular volume measurement by conductance catheter in intact dogs. Circulation 1989;80:1360-77.

19. Bishop AJ, White PA, Chaturvedi RR, Brookes CIO, Oldershaw PJ, Redington AN. The right ventricular pressurevolume cycle in patients with ischaemic heart disease. Int J Cardiol 1997;58:223-8.

20. White PA, Chaturvedi RR, Bishop AJ, Brookes CIO, Oldershaw AJ, Redington AN. Does parallel conductance vary during systole in the human right ventricle? Cardiovasc Res 1996;32:901-8

21. Karunanithi MK, Michniewicz J, Copeland SE, Feneley MP. Right ventricular preload recruitable stroke work, end-systolic pressure-volume and $\mathrm{dP} / \mathrm{dT}$ max end-diastolic volume relations compared as indices of right ventricular contractile performance in conscious dogs. Circ Res 1992;70:1169-79.

22. Kass DA, Midei M, Graves W, Brinker JA, Maughan WL. 
Use of a conductance catheter and transient inferior caval occlusion for rapid determination of pressure-volume relationships in man. Cathet Cardiovasc Diagn 1988;15:192-202.

23. Szwarc RS, Laurent D, Allegrini PR, Ball HA. Conductance catheter measurement of left ventricular volume: evidence of non-linearity within the cardiac cycle. Am J Physiol 1995;268: H1490-8.

24. Noyez L, van Son JAM, van der Werf T, Knape JTA, Gimbrere J, van Asten WNJ, et al, Retrograde coronary sinus cardioplegia in myocardial revascularization: evaluation of the influence on the fight ventricular function. Thorac Cardiovasc Surg 1992;40:209-13.

25. Rabinovitch MA, Elstein J, Chiu RC-J, Rose CP, Arzoumanian A, Burgess JA. Selective right ventricular dysfunction following coronary artery bypass grafting. J Thorac Cardiovasc Surg 1983;86:444-50.

26. Maughan WL, Shoukas AA, Sagawa K, Weisfeldt ML.
Instantaneous pressure-volume relation of the canine right ventricle. Circ Res 1979;44:304-15.

27. Brown KA, Ditchey RV. Human fight ventricalar end-systolic pressure-volume relations defined by maximal elastance. Circulation 1988;78:81-91.

28. Little WC, Cheng C-P, Mumma M, Igarishi Y, VintenJohansen $\mathbf{J}$, Johnston WE. Comparison of measures of left ventricular contractile performance derived from pressurevolume loops in conscious dogs. Circulation 1989;80:1378-87.

29. Kass DA, Maughan WL, Guo ZM, Kono A, Sunagawa K, Sagawa K. Comparative influence of load versus inotropic states on indexes of ventricular contractility: experimental and theoretical analysis based on pressure-volume relationships. Circulation 1987;76:1422-36.

30. Applegate RJ. Load dependence of left ventricular diastolic pressure-volume relations during short-term coronary artery occlusion. Circulation 1991;83:661-73.

\section{Availability of Journal back issues}

As a service to our subscribers, copies of back issues of The Journal of Thoracic and Cardiovascular Surgery for the preceding 5 years are maintained and are available for purchase from Mosby at a cost of $\$ 16.00$ per issue until inventory is depleted. The following quantity discounts are available: $25 \%$ off on quantities of 12 to 23 , and one third off on quantities of 24 or more. Please write to Mosby, Inc, Subscription Services, 11830 Westline Industrial Drive, St Louis, MO 63146-3318, or call 800-453-4351 or 314-453-4351 for information on availability of particular issues. If unavailable from the publisher, photocopies of complete issues may be purchased from UMI, $300 \mathrm{~N}$ Zeeb Rd, Ann Arbor, MI 48106, 313-761-4700. 